\title{
PERFORMANCE ANALYSIS OF THE SINGLE JET AIR CURTAIN FOR OPEN REFRIGERATED DISPLAY CABINET BY USING ARTIFICIAL NEURAL NETWORK
}

\author{
Vipin Kumar Titariya ${ }^{1 *}$, Alka Bani Agarwal ${ }^{2}$
}

\begin{abstract}
Low temperature is the key to maintain the high quality for chilled food. The single jet air curtain is used for doorways opening insulation in the current circumstances is an idealization of the single jet air curtain used in the supermarket open refrigerated display cabinets. Open refrigerated display cabinets are going through some of the changes in their thermal behavior and of its overall performance due to variations in air conditions like air curtain temperature, velocity, height/width ratio, deflection module, specific cooling load, stability and thermal efficiency. A detailed experimental and comprehensive Artificial Neural Network Analysis of air conditions and energy transfer in an open refrigerated display cabinet is performed in this study. Numerical ANN predictions are $99.77 \%$ accurate and can be used to enable quick calculations and parametric analyses for the designing purposes of open refrigeration equipment that reduce the thermal infiltration of the Open Refrigerated Display Cabinet and increase the food safety.
\end{abstract}

\section{Keywords: Air Curtain, Display Cabinet, Artificial Neural Network, Stability, Specific Cooling Load}

\section{INTRODUCTION}

Most retail food stores, functioning as supermarkets, grocery stores and convenience stores, use open refrigerated display cabinets (ORDC) to facilitate access to the product and display of the perishable product without inconvenience. Besides this commercialization feature, ORDC can be on one or more floors offering more quantity and variety of products in the available space. Therefore, vertical ORDCs are designed to market food optimally and at the same time ensure short-term storage. They are based on recycled air curtains to prevent hot air from entering the cold environment inside the appliance. An air curtain consists of a stream of air flowing through a nozzle from a honeycomb baffle on top of the refrigerated cabinet. Air curtains play a vital role in the thermal interaction of the ORDC with ambient air, since the infiltration charge of the ambient air represents approximately $72 \%$ of its cooling load [6]. The potency of the air curtain as an aerothermodynamics barrier varies with mass and thermal diffusion consequence that influences the thermal abstraction, flow instabilities and boundary effects. This will effect to the lower quality of foodstuff, higher costs and energy consumption. The performance of a refrigerated display cabinet is significantly affected by the high temperature, humidity and movement of surrounding air [9]. Although vertical ORDCs are designed primarily for supermarkets, with almost all with the air conditioning, they can be awarded in any type of retail food store. Depending on the characteristics of the store, factors such as the location of the ventilation holes of the air conditioning system, the air mass flow due to the pressure differences due to openings in the environment and the instabilities of the warm surrounding air flow influence the energy efficiency and thermal performance of display cabinet. These parameters are essential because large commercial stores spend approximately $50 \%$ of their energy on cooling load [6] and for foodstuff safety, maintenance of the foodstuff temperature is very necessary [2].

Previous studies $[4,6]$ shows that in refrigerated cabinets the temperature distribution in the refrigerated area is vulnerable to the temperature difference between the refrigerated air and the surrounding air, and it will increase in more pronounced manner in case of non-circulated single jet air curtains such as those used in building entrances where air curtains may lose relatively more power than the re-circulated curtains (such as ORDC curtains) or may have a momentum that causes a powerful impact on the ground. However, in the refrigerated cabinet, the air curtain regains momentum close to the return air grille, which can help the air curtain to maintain its integrity. A

This paper was recommended for publication in revised form by Regional Editor Omid Mahian

${ }^{1}$ Department of Mechanical Engineering, UIT, RGPV University, Bhopal, India

${ }^{2}$ Department of Mechanical Engineering, UIT, RGPV University, Bhopal, India

*E-mail address: vktitariya@gmail.com,alk_agr11@yahoo.in

Orcid id: https://orcid.org/0000-0002-5573-0305

Manuscript Received 03 July 2018, Accepted 22 October 2018 
computational study [8] has shown that in circulating air curtains, when the impulse of the air curtain is not sufficiently low, the infiltration of ambient air into the cold space is not favored by an increase in ambient temperature. This suggests that the performance of the air curtains in the insulation of one space in relation to the other is not affected by the temperature difference when the buoyancy effect is negligible; however, the amount of charge will be greater as the ambient temperature increases. In location far enough downstream of the air curtain nozzle, the loss of momentum means that the temperature gradient creates an additional transverse pressure difference $[5,10]$ which can deform the air curtain flow. In other circumstances, an unfavourable upward flow can occur due to the stack effect $[3,10]$.

\section{EXPERIMENTAL APPARATUS}

The ORDC setup has $2.0 \mathrm{~m} \times 0.6 \mathrm{~m} \times 0.5 \mathrm{~m}$. It comprises Evaporator (fins \& tube type heat exchanger); Discharge air grille; Return air grille; and Back panel with fan and shelves. The temperature of the refrigerated section is provided by the mass flow of refrigerated air that leaves the discharge air grille, then through the back panel and comes back to the return air grille to refrigerate again inside the evaporator. The airflow comes down from the Discharge air grille in forms of an air curtain that protects the inner refrigerated compartment. The copper capillary tube is mounted near the evaporator to maintain the refrigerant temperature at $5^{\circ} \mathrm{C}$.

The device has three $15 \mathrm{~W}$ fans each to provide a flow rate of $0.4 \mathrm{~m}^{3} / \mathrm{s}$ to unload the air grille and back panel. The air, before reaching the air discharge grid, passes through an evaporator of dimensions $0.5 \mathrm{~m} \times 0.15 \mathrm{~m} \times$ $0.3 \mathrm{~m}$ consisting of 135 fins and four rows of tubes in the direction of flow of air and eight rows of tubes perpendicular to it. The Discharge air grille has a total width, $\mathrm{b}_{\mathrm{s}}$, of $0.05 \mathrm{~m}$, which is evenly distributed to form the air curtain of $0.035 \mathrm{~m}$. This equipment is used to display products with a temperature class $\mathrm{M} 1\left(-1^{\circ} \mathrm{C}\right.$ to $\left.+5^{\circ} \mathrm{C}\right)$. A compressor and an air condenser have been installed. The measuring instruments were selected to obtain reliable measurements of the relevant physical properties.

Table 1. Experimental devices use for measurement

\begin{tabular}{llll}
\hline Experimental device & Model & Measuring range & Accuracy \\
\hline Temperature Sensor & K type thermocouple & $-20^{\circ} \mathrm{C}$ to $+100^{\circ} \mathrm{C}$ & $\pm 0.2{ }^{\circ} \mathrm{C}$ \\
Hygrometry & $485 \mathrm{~B}-1$ & $15 \%$ to $90 \%$ & $\pm 2 \%$ \\
Hot wire anemometer & AVM08 & $0.05 \mathrm{~m} / \mathrm{s}$ to $1 \mathrm{~m} / \mathrm{s}$ & $\pm 2 \%$ \\
Flow Meter & GM8908 & 0 to $30 \mathrm{~m} / \mathrm{s}$ & $\pm 0.2 \%$ \\
Pressure Transducer & MPXV2010DP NXP & 0 to $200 \mathrm{psig}$ & $\pm 0.5 \%$ \\
\hline
\end{tabular}

The experimental tests followed the standard ISO 23953-2:2015(en) [2] and were experimental chamber designed according to the standard. The 485B-1 air humidity and temperature sensors were placed in the discharge air grille, return air grille and environment. The type $\mathrm{K}$ thermocouple of the temperature sensors was placed in the test M-packages (product simulators). Table 1 shows the experimental techniques and measuring devices used to collect the relevant physical properties.

Following relations are used for experimental studies [3]: Air Curtain Deflection Modulus,

$$
D_{m}=\frac{\rho_{s} b_{s} v_{s}^{2}}{g H^{2}\left(\rho_{a, i n t}-\rho_{a, a m b}\right)}
$$

Specific Cooling Load on ORDC,

Air Curtain Stability,

$$
Q_{c a b, A}=\frac{c_{p} \rho_{s} b_{s} v_{s}\left(t_{a, s}-t_{a, e}\right)}{L H}
$$

$$
\frac{y}{H}=1
$$

Air Curtain Thermal Efficiency, 
Journal of Thermal Engineering, Technical Note, Vol. 6, No. 3, pp. 359-368, April, 2020

$$
\eta_{\text {thermal }}=\frac{t_{a, a m b}-t_{a, e}}{t_{a, a m b}-t_{a, s}}
$$

Table 2. Different height/width ratio used for experimental analysis with respect to variation in air curtain height

\begin{tabular}{ccccc}
\hline $\mathbf{H}(\mathbf{m})$ & \multicolumn{5}{c}{$\mathbf{H} / \mathbf{b}_{\mathbf{s}}$} \\
\hline 0.3 & 5 & 10.7 & -- & -- \\
0.535 & -- & -- & 13.4 & - \\
0.8 & 5 & -- & 13.4 & 28.6 \\
\hline
\end{tabular}

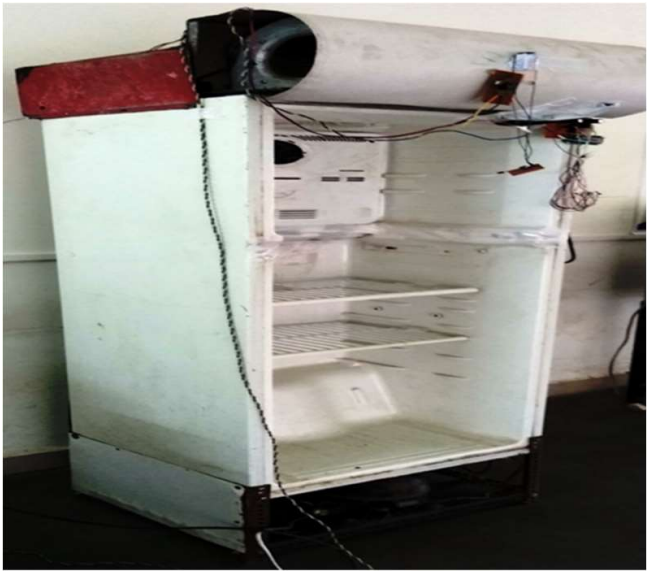

Figure 1. Open refrigerated display cabinet experimental setup

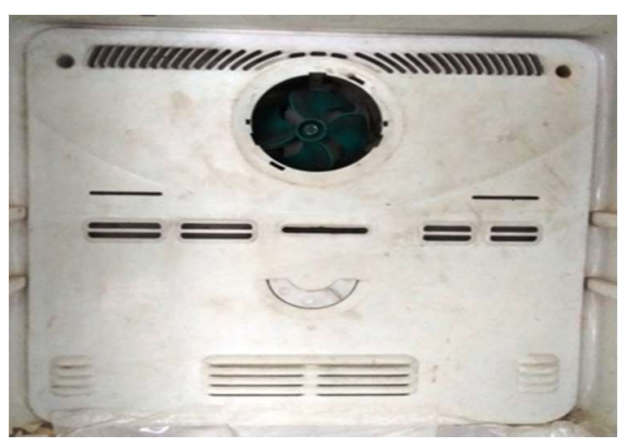

Figure 2. Back panel for ORDC

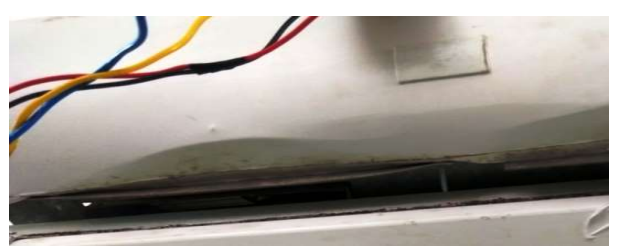

Figure 3. Discharge air grille for ORDC

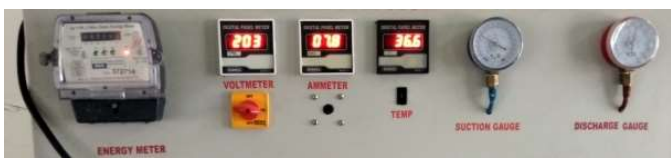

Figure 4. Measuring devices for ORDC 
The performance of the single jet air curtain in a showcase was studied through the integration of experimental work and analysis of artificial neural networks with the objective of developing a methodology for the study of single jet air curtains in non-isothermal conditions. The experience of analyzing the air flow in the shelves inside the refrigerated cabinet makes it difficult to calculate low air velocities with precision only when using hot wire anemometers. Numerous authors $[3,4,5,7,10]$ used temperature measurements to calibrate their simulation models and that the thermocouples were used to measure the temperature in a rake. According to several authors [3, $5,10]$, the performance of the single jet air curtain depends mainly on the height/width ratio $\left(\mathrm{H} / \mathrm{b}_{\mathrm{S}}\right)$ and the speed of the air jet of the air curtain.

According to Schlichting [11], width of the air curtain is the only parameter that affects the length of the transition zone; therefore, its stability is managed with a height/width ratio, $\mathrm{H} / \mathrm{b}_{\mathrm{s}} \leq 5.2$, for low turbulence intensities of $\leq 0.1 \%$. This will indicate that a height/width ratio of less than 5.2 would mean that the velocity of the single-jet air curtain would be managed from the delivery position to the extractor grid of the refrigerated cabinet.

Table 3. Air curtain performance result for ORDC-experimental results

\begin{tabular}{|c|c|c|c|c|c|c|c|c|}
\hline $\begin{array}{c}\text { Height, } \\
\text { m }\end{array}$ & $\begin{array}{c}\text { velocity, } \\
(\mathrm{m} / \mathrm{s})\end{array}$ & $\mathbf{H} / \mathbf{b}_{\mathrm{s}}$ & $\begin{array}{c}\text { Temp., }{ }^{\circ} \mathrm{C}, \\
\mathbf{t}_{\mathrm{a}, \text { internal }}\end{array}$ & $\begin{array}{c}\text { Temp., }{ }^{\circ} \mathbf{C}, \\
\mathbf{t}_{\mathrm{a}, \text { external }}\end{array}$ & $\begin{array}{c}\text { Deflection } \\
\text { modulus }\end{array}$ & $\begin{array}{l}\text { Sp. Cooling } \\
\text { Load }\left(w / \mathbf{m}^{2}\right)\end{array}$ & $\begin{array}{l}\text { Stabilit } \\
\mathbf{y}(\mathbf{y} / \mathbf{H})\end{array}$ & $\begin{array}{c}\boldsymbol{\eta} \\
\text { thermal }\end{array}$ \\
\hline 0.8 & 0.3 & 28.6 & 10.3 & 13.5 & 0.00 & 191 & 0.05 & 46.2 \\
\hline 0.8 & 0.6 & 28.6 & 9.4 & 9.8 & 0.01 & 265 & 0.09 & 61.4 \\
\hline 0.8 & 0.8 & 28.6 & 8.8 & 9.1 & 0.03 & 330 & 0.15 & 64.0 \\
\hline 0.8 & 1.0 & 28.6 & 8.3 & 8.7 & 0.08 & 392 & 0.22 & 66.0 \\
\hline 0.8 & 2.0 & 28.6 & 8.0 & 7.4 & 0.21 & 676 & 0.50 & 70.2 \\
\hline 0.8 & 0.3 & 13.4 & 1.8 & 8.9 & 0.00 & 262 & 0.08 & 64.1 \\
\hline 0.8 & 0.6 & 13.4 & 1.6 & 6.4 & 0.03 & 370 & 0.37 & 75.0 \\
\hline 0.8 & 0.8 & 13.4 & 1.5 & 5.7 & 0.09 & 438 & 0.44 & 77.9 \\
\hline 0.8 & 1.0 & 13.4 & 1.3 & 5.1 & 0.11 & 496 & 0.50 & 80.0 \\
\hline 0.8 & 2.0 & 13.4 & 1.0 & 4.4 & 0.44 & 840 & 0.63 & 83.4 \\
\hline 0.8 & 0.3 & 5 & 2.1 & 4.9 & 0.00 & 380 & 0.12 & 81.0 \\
\hline 0.8 & 0.6 & 5 & 2.0 & 2.5 & 0.10 & 384 & 0.49 & 90.0 \\
\hline 0.8 & 0.8 & 5 & 1.6 & 1.9 & 0.18 & 390 & 0.56 & 92.2 \\
\hline 0.8 & 1.0 & 5 & 1.5 & 1.8 & 0.29 & 416 & 0.62 & 93.6 \\
\hline 0.8 & 2.0 & 5 & 1.3 & 1.3 & 1.18 & 690 & 0.75 & 94.4 \\
\hline 0.535 & 0.3 & 13.4 & 1.2 & 7.3 & 0.04 & 211 & 0.10 & 71.3 \\
\hline 0.535 & 0.6 & 13.4 & 1.2 & 7.3 & 0.09 & 420 & 0.11 & 71.4 \\
\hline 0.535 & 0.8 & 13.4 & 1.2 & 6.6 & 0.11 & 507 & 0.13 & 74.0 \\
\hline 0.535 & 1.0 & 13.4 & 1.1 & 6.1 & 0.19 & 588 & 0.14 & 76.0 \\
\hline 0.535 & 1.5 & 13.4 & 1.3 & 5.3 & 0.40 & 762 & 0.19 & 79.1 \\
\hline 0.535 & 2.0 & 13.4 & 1.2 & 3.2 & 0.71 & 604 & 0.46 & 87.7 \\
\hline 0.3 & 0.3 & 10.7 & 0.3 & 9.1 & 0.08 & 315 & 0.12 & 64.2 \\
\hline 0.3 & 0.6 & 10.7 & 0.2 & 5.6 & 0.19 & 404 & 0.24 & 77.5 \\
\hline 0.3 & 0.8 & 10.7 & 0.2 & 4.1 & 0.30 & 396 & 0.38 & 84.0 \\
\hline 0.3 & 1.0 & 10.7 & 0.2 & 3.5 & 0.46 & 422 & 0.58 & 86.1 \\
\hline 0.3 & 1.5 & 10.7 & 0.2 & 3.1 & 0.99 & 540 & 1.00 & 87.8 \\
\hline 0.3 & 2.0 & 10.7 & 0.3 & 2.8 & 1.73 & 680 & 1.00 & 88.0 \\
\hline 0.3 & 0.3 & 5 & 0.1 & 5.6 & 0.08 & 418 & 0.21 & 77.5 \\
\hline 0.3 & 0.6 & 5 & 0.0 & 1.9 & 0.29 & 300 & 0.98 & 92.5 \\
\hline 0.3 & 0.8 & 5 & 0.1 & 1.6 & 0.50 & 319 & 1.00 & 94.0 \\
\hline 0.3 & 1.0 & 5 & 0.1 & 1.4 & 0.83 & 388 & 1.00 & 95.1 \\
\hline 0.3 & 1.5 & 5 & 0.1 & 1.3 & 1.81 & 508 & 1.00 & 95.5 \\
\hline 0.3 & 2.0 & 5 & 0.2 & 1.2 & 3.25 & 640 & 1.00 & 95.6 \\
\hline
\end{tabular}


Journal of Thermal Engineering, Technical Note, Vol. 6, No. 3, pp. 359-368, April, 2020

\section{ARTIFICIAL NEURAL NETWORK}

A neural network is a computer tool, which is basically a tool to create a computer model of the brain. The main goal of this tool is to generate a computer system to perform different tasks faster than other traditional systems. These activities include model classification, recognition, approximation, optimization and aggregation of data.

Artificial Neural Network (ANN) is a regression tool whose main work is to prepare an analogy for the biological neural network system. Regression Network Analysis system (RNA) is also known as "artificial neural network systems" or "parallel distributed processing systems" or "connection systems". ANN required a large collection of parametric data to interconnect the computational model to allow communication between the data. These parameters, also called nodes or neurons, are simple computational processors that operate in parallel [1].

Every neuron is linked in an association. Each link is connected to a weight with information on the input signal. This signal is useful for the neurons to solve a particular problem because this will usually excite the signal so that each neuron will have an internal state, called the characteristic signal. The output signals, which are generated by the combination of the activation rule and the input signals, can be used for other units.

\section{ANN MODELLING}

The present work involved the development of an artificial neural network model that could predict the performance of the air curtain for an open refrigerated display case. The main objective of the current work was to use neural networks to model the flow parameter. The MATLAB Neural Network Toolbox (R2016a) was used to design the neural network. The basic stages of design are data collection; data analysis and preprocessing; neural network design; training and testing of neural networks; simulation and prediction with neural networks and postprocessing analyze the experimental result with predicted one. The ANN technique has been used to predict the performance of the air curtain according to the parameters.

The purpose of this work is to relate the parameters that affect the performance of an air curtain. The air curtain is the component that has a greatest effect on the energy consumption of a refrigerated cabinet. To increase the performance of the air curtains, there is a need of methods to modify the performance of air curtains.

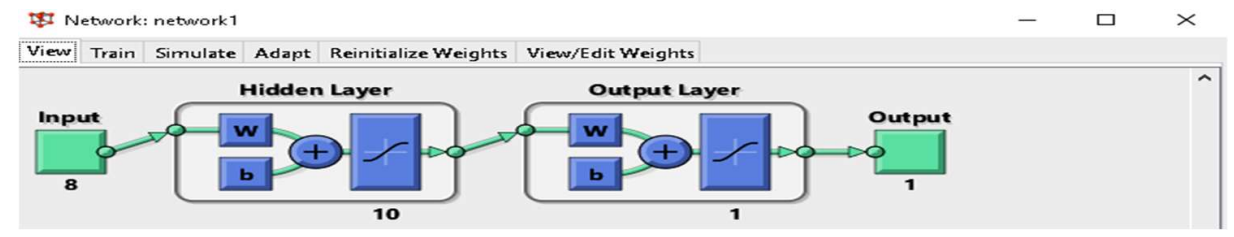

Figure 5. Artificial Neural Network of Air Curtain performance parameters for ORDC

\section{PROPOSED MODEL}

In this study, the Artificial Neural Network based analytical model is proposed, in which Multi-Layer Feed Forward Network is used.

Table 4. Neural network input variables

\begin{tabular}{cccc}
\hline Input Data & Range & Input Data & Range \\
\hline Air Curtain Height in ORDC & $0.3,0.535 \& 0.8$ & Deflection modulus of Air Curtain & $0-3.25$ \\
Velocity of Air Curtain & $0.3-2 \mathrm{~m} / \mathrm{s}$ & $\begin{array}{c}\text { Air Curtain Stability } \\
\text { Specific Cooling Load on Air }\end{array}$ & $\begin{array}{c}191-762 \mathrm{w} / \mathrm{m}^{2} \\
\text { Height to Width ratio of Air } \\
\text { Curtain }\left(\mathrm{H} / \mathrm{b}_{\mathrm{s}}\right)\end{array}$ \\
$\begin{array}{c}\text { Curtain } \\
\text { Temperature Inside The Cabinet } \\
\left(\mathrm{t}_{\mathrm{a} \text {, internal }}\right)\end{array}$ & $0.0-10.3{ }^{\circ} \mathrm{C}$ & $\begin{array}{c}\text { Thermal Efficiency of Air Curtain } \\
\left(\eta_{\text {thermal }}\right)\end{array}$ & $46.2-95.6 \%$ \\
$\begin{array}{c}\text { Temperature Inside The Cabinet } \\
\left(\mathrm{t}_{\mathrm{a}, \text { external }}\right)\end{array}$ & $1.2-13.5{ }^{\circ} \mathrm{C}$ & & \\
\hline
\end{tabular}


Journal of Thermal Engineering, Technical Note, Vol. 6, No. 3, pp. 359-368, April, 2020

Table 5. Various elements of structure

\begin{tabular}{cc}
\hline Neural Network & MLP \\
\hline Number of Input Variables & 9 \\
Number of Hidden Layer & 2 \\
Number of Hidden Neuron in First Hidden layer & 10 \\
Activation function used in first hidden layer & Straight line \\
\hline
\end{tabular}

Table 6. Value of regression coefficient

\begin{tabular}{ccc}
\hline S. No. & Data set & Value of R \\
\hline 1 & Training & 0.99778 \\
2 & Validation & 1 \\
3 & Test & 0.9982 \\
4 & All & 0.9977 \\
\hline
\end{tabular}

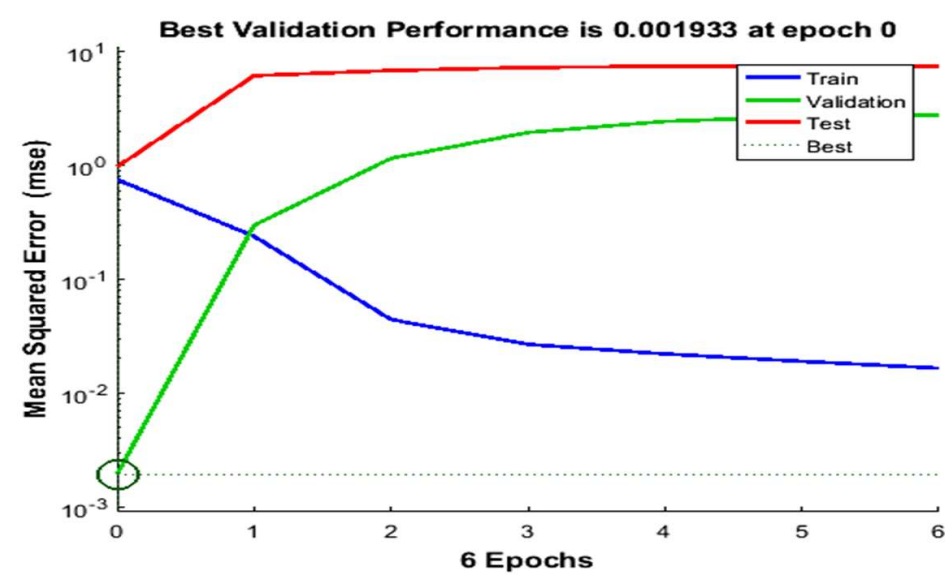

Figure 6. MATLAB ANN training performance

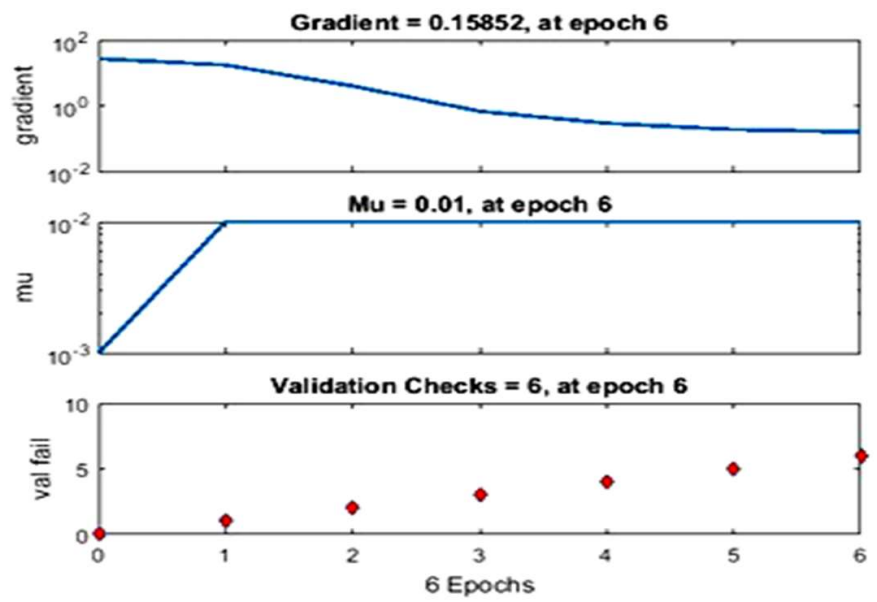

Figure 7. MATLAB ANN training status 
Different figures provide the results of all the three data set using training, testing and validation data with whole data considering the value of ' $r$ ' correlation coefficient. Value of ' $r$ ' indicates similarity between two data series, its value ranges from -1 to +1 . A larger value of ' $r$ ' indicates better correlation. It has been observed from Table 5, that value of ' $r$ ' between the output from model and target value, for all the three sets of data, is reaching ' 1 ' which indicates a good correlation.
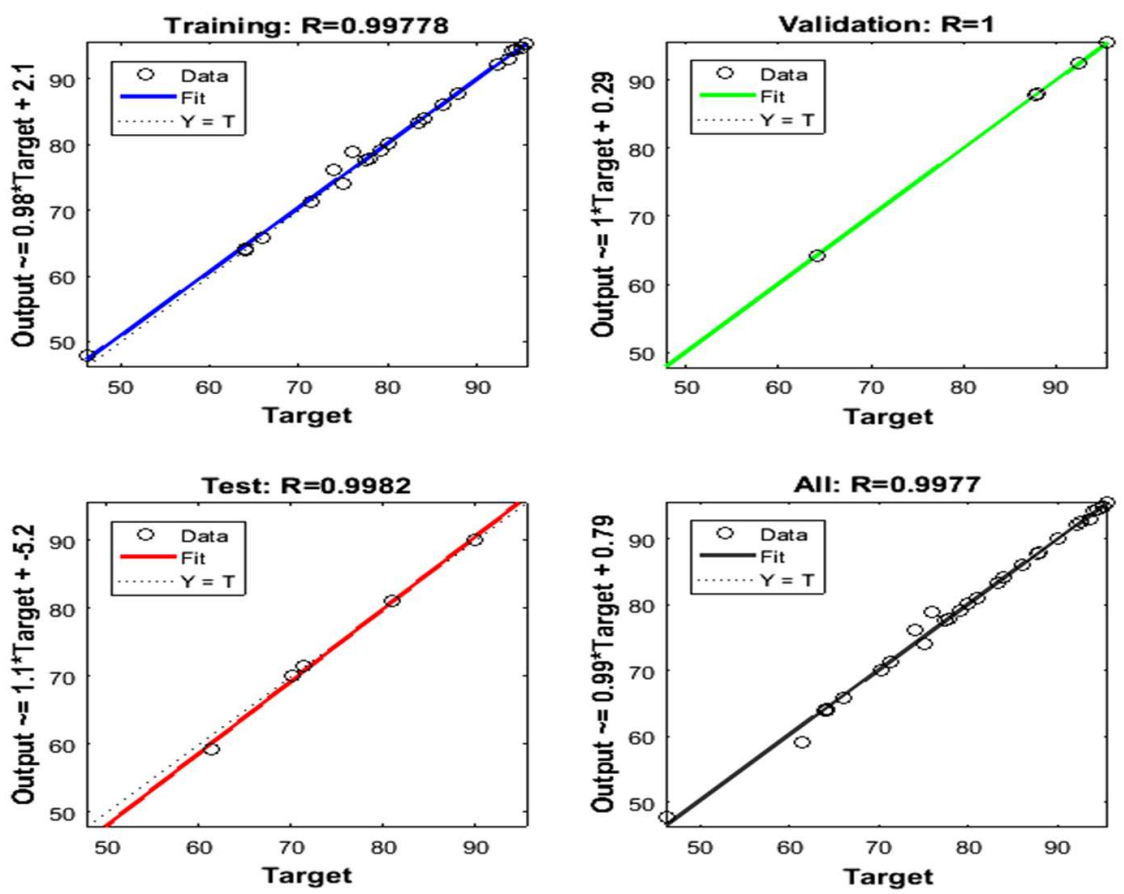

Figure 8. MATLAB ANN regression chart

\section{RESULTS AND DISCUSSION}

This work is based on the results obtained by Gaspar et al. and Nascimento, S. M., et al. [7, 9] through the development of experimental studies aimed at optimizing thermal performance with air flow adjustment between the Discharge air grille and Return air grille. The results showed that adjusting the airflow between the Discharge air grille and Return air grille has improved ORDC performance by $10 \%$. These results will be used in the development of new products on an industrial scale.

A total of 33 different experimental results determined from equations given by different authors $[3,5,10]$ and employed as a database for the training, test and validation sets. Out of 33 experimental results, a set of 23 results are used to train the ANN models. Out of remaining 10, a set of 5 is used for testing and rest 5 is used to validate the model. This trained $\mathrm{ANN}$ is used to obtain the output values.

In this work, Air Curtain thermal efficiency for open refrigerated display cabinet is predicted through the prepared ANN model by utilizing experimental results as an inputs (Height, Height/width ratio, Velocity, Temperature inside Air Curtain, Temperature outside Air Curtain, Deflection Module, Stability and Specific Cooling Load) and ANN predicted results are compared with the experimental one. The values are tabulated in Table 7 and the comparison of the Air Curtain Thermal Efficiency values for both the results is shown in different figures. 
Journal of Thermal Engineering, Technical Note, Vol. 6, No. 3, pp. 359-368, April, 2020

Table 7. Predicted artificial neural network results

\begin{tabular}{|c|c|c|c|}
\hline Serial No & Experimental $\eta_{\text {thermal }}$ & $\begin{array}{c}\text { ANN } \\
\eta_{\text {thermal }}\end{array}$ & Error in predicted $\eta_{\text {thermal }}$ \\
\hline 1 & 46.2 & 47.81675 & -1.61675 \\
\hline 2 & 61.4 & 59.20017 & 2.199832 \\
\hline 3 & 64.0 & 63.87599 & 0.124008 \\
\hline 4 & 66.0 & 65.88371 & 0.116289 \\
\hline 5 & 70.2 & 70.12111 & 0.078889 \\
\hline 6 & 64.1 & 64.06198 & 0.038024 \\
\hline 7 & 75.0 & 73.9545 & 1.045496 \\
\hline 8 & 77.9 & 77.88942 & 0.010581 \\
\hline 9 & 80.0 & 80.19313 & -0.19313 \\
\hline 10 & 83.4 & 83.40223 & -0.00223 \\
\hline 11 & 81.0 & 81.02699 & -0.02699 \\
\hline 12 & 90.0 & 90.0337 & -0.0337 \\
\hline 13 & 92.2 & 92.21897 & -0.01897 \\
\hline 14 & 93.6 & 92.94911 & 0.650888 \\
\hline 15 & 94.4 & 94.39267 & 0.007331 \\
\hline 16 & 71.3 & 71.35288 & -0.05288 \\
\hline 17 & 71.4 & 71.42447 & -0.02447 \\
\hline 18 & 74.0 & 76.24184 & -2.24184 \\
\hline 19 & 76.0 & 78.80108 & -2.80108 \\
\hline 20 & 79.1 & 79.10732 & -0.00732 \\
\hline 21 & 87.7 & 87.69234 & 0.007663 \\
\hline 22 & 64.2 & 64.26188 & -0.06188 \\
\hline 23 & 77.5 & 77.55387 & -0.05387 \\
\hline 24 & 84.0 & 84.04625 & -0.04625 \\
\hline 25 & 86.1 & 86.12868 & -0.02868 \\
\hline 26 & 87.8 & 87.81737 & -0.01737 \\
\hline 27 & 88.0 & 88.0246 & -0.0246 \\
\hline 28 & 77.5 & 77.53901 & -0.03901 \\
\hline 29 & 92.5 & 92.45009 & 0.049913 \\
\hline 30 & 94.0 & 94.19134 & -0.19134 \\
\hline 31 & 95.1 & 94.78272 & 0.317282 \\
\hline 32 & 95.5 & 95.44276 & 0.057237 \\
\hline 33 & 95.6 & 95.54822 & 0.051778 \\
\hline
\end{tabular}




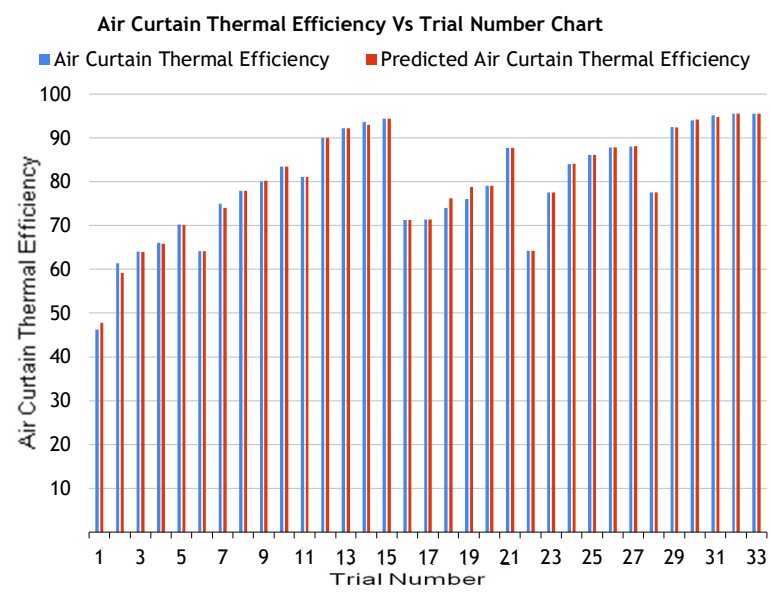

Figure 9. Experimental and predicted ANN results

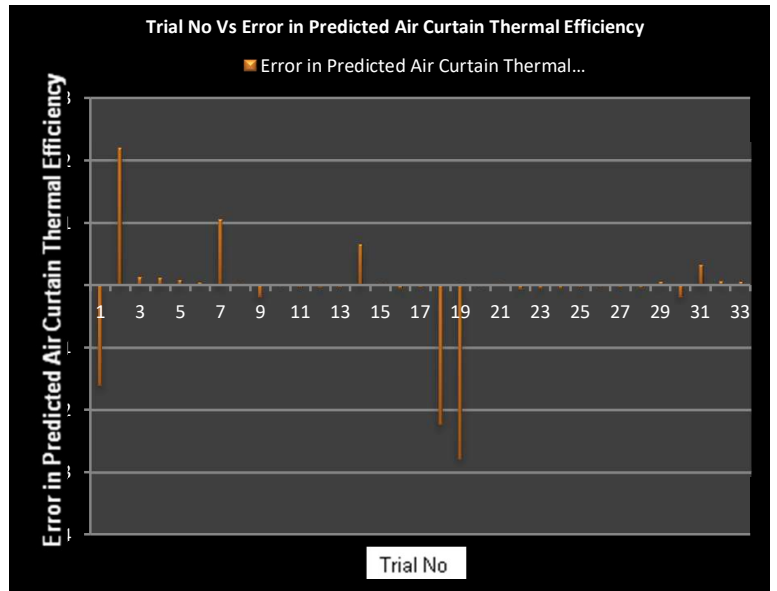

Figure 10. Errors in predicted ANN results

The outputs produced by the model have been compared with the target outputs which are the Air Curtain Thermal Efficiency obtained experimentally. Generalization ability of the developed network is measured by the Mean Square Error (MSE). Figure 6 shows the Mean square error for six epochs in all the three runs during the ANN training. It has been observed that MSE decreased after each run and the best results found at 0 epochs.

\section{CONCLUSION REMARKS}

The Predicted Air Curtain Thermal Efficiency is taken as a target value of the program, whereas the height, velocity, height/width ratio, the temperature inside Air Curtain, Temperature outside Air Curtain, Deflection Module, Specific Cooling Load and Air Curtain Stability were taken as the input values of the program. Hence the Predicted Air Curtain Thermal Efficiency value on the basis of eight parameters has arrived for the variable Sample Air Curtain Thermal Efficiency. Similarly, we can predict the Air Curtain Thermal Efficiency for different variable air curtain velocities. According to the regression analysis, it will be about $99.77 \%$ accurate and can be used for designing purpose by forecasting the parametric analysis of Air curtain with respect to different models of Open Refrigerated Display Cabinets.

An empirical model has been developed by using Artificial Neural Network to determine the Air Curtain Thermal Efficiency. ANN prediction would have been more accurate if the experimental results will be more. This study demonstrates the ability of the artificial neural network as a brilliant technique in order to predict the performance of 
the Air Curtain with varying input variables. The model implemented satisfactorily in the prediction of Air Curtain Thermal Efficiency with different variables. The prediction made by using proposed model shows a high degree of accuracy for Air Curtain Thermal Efficiency obtained through the model.

\section{NOMENCLATURE}

$\begin{array}{ll}b_{s} & \text { Width of the air curtain [m] } \\ C_{p} & \text { Specific heat at constant pressure of air }[\mathrm{J} / \mathrm{Kg} \mathrm{K}] \\ D_{m} & \text { Deflection module } \\ g & \text { Specific gravity }\left[\mathrm{kg} / \mathrm{m}^{3}\right] \\ H & \text { Height of the air curtain }[\mathrm{m}] \\ \mathrm{H} / \mathrm{b}_{\mathrm{s}} & \text { Height by width ratio for the air curtain } \\ L & \text { Length of air curtain [m] } \\ \text { ORDC } & \text { Open refrigerated display cabinet } \\ Q_{c a b, A} & \text { Specific cooling load in the cabinet }[\mathrm{KW}] \\ t_{a, a m b} & \left.\text { Temperature of ambient air [ }{ }^{\circ} \mathrm{C}\right] \\ t_{a, e} & \text { Temperature at return air grille of air curtain }\left[{ }^{\circ} \mathrm{C}\right] \\ \mathrm{t}_{\mathrm{a}, \text { external }} & \text { Temperature external of ORDC }\left[{ }^{\circ} \mathrm{C}\right] \\ \mathrm{t}_{\mathrm{a}, \text { internal }} & \text { Temperature internal of ORDC [ } \mathrm{C}] \\ t_{a, s} & \text { Temperature at discharge air grille of air curtain }\left[{ }^{\circ} \mathrm{C}\right] \\ v_{s} & \text { Velocity of the air curtain }[\mathrm{m} / \mathrm{s}] \\ y & \text { Y axis coordinate for air curtain stability }\end{array}$

\section{GREEK SYMBOLS}

$\begin{array}{ll}\rho_{s} & \text { Density of the air supply }\left[\mathrm{kg} / \mathrm{m}^{3}\right] \\ \rho_{a, \text { int }} & \text { Density of air inside the ORDC }\left[\mathrm{kg} / \mathrm{m}^{3}\right] \\ \rho_{a, \text { amb }} & \text { Density of air outside the ORDC }\left[\mathrm{kg} / \mathrm{m}^{3}\right] \\ \eta_{\text {thermal }} & \text { Air curtain thermal efficiency }\end{array}$

\section{REFERENCES}

[1] Akash MS. Artificial intelligence \& neural networks. International Journal of Soft Computing and Artificial Intelligence. 2015; 3(2), 37-44.

[2] ASHRAE Handbook: Refrigeration, American Society of Heating, Refrigerating and Air-Conditioning Engineers Incorporation. 2015.

[3] Axell, M, Fahlén P. Design criteria for energy efficient vertical air curtains in display cabinets. Proceedings of 21st IIR International Congress of Refrigeration 2003; Washington DC, U.S.A.

[4] Chen, YG., Yuan XL. Experimental study of the performance of single-band air curtains for multi-deck refrigerated display cabinet. Journal of Food Engineering 2005; 69(3), 261-267. doi:10.1016/j.jfoodeng.2004.08.016

[5] Cortella, G, Manzan M, Comini G. CFD simulation of refrigerated display cabinets. International Journal of Refrigeration 2001; 24(3), 250-260. doi:10.1016/S0140-7007(00)00015-3.

[6] Faramarzi, R. Efficient display case refrigeration, ASHRAE Journal 1999, 41(11).

[7] Gaspar, PD, Gonçalves LCC, Pitarma RA. Experimental analysis of the thermal entrainment factor of air curtains in vertical open display cabinets for different ambient air conditions. Applied Thermal Engineering 2011; 31(5), 961-969. doi:10.1016/j.applthermaleng.2010.11.020.

[8] Gray I, Luscombe P, McLean L, Sarathy CSP, Sheahen P, Srinivasan K. Improvement of air distribution in refrigerated vertical open front remote supermarket display cases. International Journal of Refrigeration 2008; 31(5), 902-910. doi:10.1016/j.ijrefrig.2007.09.005.

[9] Nascimento, SM, Heidinger GG, Gaspar PD, Silva PD. Experimental study of the interference in air curtains due to the parallel transfer in front of refrigerated display cases. Proceedings of the ASME 2014 12th Biennial Conference on Engineering Systems 2014; Design and Analysis, Denmark.

[10] Navaz, HK, Faramarzi R, Gharib M, Dabiri D, Modarress D. The application of advanced methods in analyzing the performance of the air curtain in a refrigerated display case. Transactions ASME Journal of Fluids Engineering 2002; 124, 756-64. doi:10.1115/1.1478586.

[11] Schlichting, H. Boundary-layer theory, New York: McGraw-Hill 1955, 535. 